IIIIIIIIIIIIIIIIIIIIIIIIIIIIIIIIIIII

Original Article

IIIIIIIIIIIIIIIIIIIIIIIIIIIIIIIIIII

\title{
Modeling of runoff water and runoff pesticide concentrations in upland bare soil using improved SPEC model
}

\author{
Lam Van Thinh, ${ }^{1,2}$ Ishwar Chandra Yadav, ${ }^{3}$ Julien Boulange, ${ }^{4}$ \\ Dang Quoc ThuYeT ${ }^{5}$ and Hirozumi WaTANabe ${ }^{3, *}$ \\ ${ }^{1}$ United Graduate School of Agricultural Science, Tokyo University of Agriculture and Technology, Tokyo, Japan \\ ${ }^{2}$ College of Environment and Natural Resources, Can Tho University, Can Tho City, Vietnam \\ ${ }^{3}$ Department of International Environmental and Agricultural Science, Tokyo University of Agriculture and Technology, Tokyo, Japan \\ ${ }^{4}$ Center for Global Environmental Research, National Institute for Environmental Science, 16-2 Onogawa, Tsukuba, Japan \\ ${ }^{5}$ Department of Biological and Environmental Engineering, Graduate School of Agricultural and Life Sciences, The University of Tokyo, Japan
}

(Received January 17, 2019; Accepted March 20, 2019)

\begin{abstract}
The SPEC model (Predicted Environmental Concentrations in agricultural Soils) was developed and improved for the simulation of pesticide runoff. The model was applied to the Sakaecho upland bare soil field (Tokyo, Japan) to predict runoff water, sediment concentration in runoff water, pesticide concentrations in runoff water, and runoff sediment (clothianidin and imidacloprid) under artificial rainfall conditions. The results showed that the simulated time to first runoff agreed very well with the observed data. The simulated cumulative runoff, sediment yield, and imidacloprid concentration in sediment agreed well with the observed data (Nash-Sutcliffe Efficiency (NSE) $>0.75$ ). The simulated runoff rate agreed reasonably well with the observed data (NSE >0.5). The predicted clothianidin concentrations in sediment and in runoff water had acceptable agreement with the observed data (NSE $>0$ ). The results implied the model's potential to predict runoff water, sediment yield, and pesticide runoff. (C) Pesticide Science Society of Japan

Keywords: Runoff, pesticide concentration, SPEC model, upland bare soil.
\end{abstract}

Electronic supplementary materials: The online version of this article contains supplementary material (Equations; Table S1 and S2), which is available at http://www.jstage.jst.go.jp/browse/jpestics/

\section{Introduction}

Pesticide use improves agricultural productivity; however, its application could pose some environmental risks to soil, water, plants, and animals. ${ }^{1,2)}$

To control the negative environmental impacts of pesticide use, it is necessary to quantify the pesticide residue in the environment. Compared to expensive and time-consuming environmental monitoring, the use of mathematical models is considered to be a more efficient way to achieve environmental assessment of pesticide fate. ${ }^{3-5)}$ In recent years, water quality models have been widely used as supporting tools for Environmental Impact Assessment (EIA). ${ }^{6)}$ In Japan, many mathematical models were developed to simulate pesticides in catchment as well as plot scales for paddy fields, ${ }^{3,7-12)}$ but very few models were developed to apply in upland fields. ${ }^{8}$

SPEC, a pesticide fate and transport model for assessing SoilPEC (Predicted Environmental Concentrations in agricultural

\footnotetext{
* To whom correspondence should be addressed.

E-mail: pochi@cc.tuat.ac.jp

Published online May 30, 2019

(c) Pesticide Science Society of Japan
}

soils), was developed to simulate pesticides in upland fields and has been successfully validated. ${ }^{8)}$ This model requires fewer input parameters, overcoming the difficulty of obtaining sufficient parameters when using other mathematic models. In addition, because it was coded in Excel Visual Basic Application (Excel VBA), it is easy to use in terms of data input and output display. However, there are still some limitations in this model. It simulates pesticide presence in only two soil layers; the runoff module and pesticide concentration in runoff were inappropriately developed; and the simulation of sediment yield and sediment pesticide levels was not available.

The validation of runoff was not conducted in the SPEC model due to a lack of runoff data. Using artificial rainfall data from a rainfall simulator could be an alternative to generating rainfall and runoff data on a plot scale in a small time step (minute base). However, hourly is the smallest time step used in the previous SPEC model, and thus the runoff data in a smaller time step generated by a rainfall simulator could not be applied in previous SPEC models for calibration and validation.

For runoff simulation, the Soil Conservation Service (now the National Resources Conservation Service) Curve Number (CN) method has been applied in many models to simulate runoff., ${ }^{43-20)}$ This method is popular because it is simple and has 
been successfully applied to simulate runoff in many soil types and regions. ${ }^{4,13-20)}$ However, some authors reported that the default initial abstraction in the $\mathrm{CN}$ method was not appropriate for runoff simulation for soils in some countries. ${ }^{21-28)}$

The objectives of this study were (1) to develop a pollutant runoff model that simulates runoff water, sediment concentration and yield in runoff water, and pesticide concentrations in runoff water and sediment; and (2) to apply this model to validate the case study of plot-scale monitoring of pesticide runoff from bare soil under artificial rainfall conditions.

\section{Materials and Methods}

1. Mathematical model-Predicted Environmental Concentration in agricultural soils (SPEC)

\subsection{Runoff simulation}

The CN method was originally developed by the Soil Conservation Service (now the Natural Resources Conservation Service, NRCS). ${ }^{29-31)}$ This method has been used in many models to simulate runoff., ${ }^{4-20)}$

In this study, instead of using rainfall volume in every time interval to generate runoff, the cumulative rainfall was used to calculate the cumulative runoff volume.

The cumulative runoff $Q^{30)}$ is determined by a general equation as follows:

$$
Q_{j}=\frac{\left(P_{j}-I_{a j}\right)^{2}}{\left(P_{j}-I_{a j}+S_{j}\right)} \quad \text { for } \quad P_{j}>I_{a j}
$$

where $j$ is time step $j^{\text {th }}, Q$ is the cumulative runoff (in $\mathrm{mm}$ ), $P$ is cumulative rainfall (in $\mathrm{mm}$ ), $I_{a}$ is the initial abstraction (in $\mathrm{mm}$ ), and $S$ is the retention parameter (in $\mathrm{mm}$ ).

Let $\lambda=I_{a} / S$, where $\lambda$ is an initial abstraction ratio (unitless), and substituting this parameter into Eq. (1) gives

$$
Q_{j}=\frac{\left(P_{j}-\lambda * S_{j}\right)^{2}}{\left(P_{j}+(1-\lambda)^{*} S_{j}\right)} \quad \text { for } \quad P_{j}>I_{a j}
$$

The original value of $\lambda$ was equal to $0.2 .^{22,27,29-31)}$ However, other values of $\lambda$ were reported for some regions. ${ }^{21-28)}$ Therefore, in this study, the $\lambda$ parameter will be determined for the study area through calibration and validation.

The subtraction of two continuous Q values determines the runoff rate $d Q$ (in $\mathrm{mm} /$ time step),

$$
d Q_{j}=Q_{j}-Q_{j-1} \quad \text { for } \quad P_{j}>0
$$

The retention parameter $S$ depends on rate of infiltration at the soil surface and the amount of water storage available in the soil profile. The relationship of $S$ (in $\mathrm{mm}$ ) to the runoff curve number $\mathrm{CN}$ (CN is a transformation of $S$ ) was defined in the previous study. ${ }^{8)}$ The details for updating $S$ were also defined in Boulange et al. ${ }^{8}$ )

In every time step, the water content in every soil layer is updated as a function of input water from infiltration or percolation from right above the layer and evaporation from that soil layer. The evaporation from the soil layer is determined using the method specified in Neitsch et al. (2011). ${ }^{32)}$

\subsection{Sediment simulation}

The sediment module was developed in a specific case for bare soil conditions, based on the modified universal soil loss equation (MUSLE) developed by Williams. ${ }^{33)}$ The MUSLE in US units of feet and inches for length, acres for area, and tons for mass was converted into SI units ${ }^{34)}$ as follows:

$$
\operatorname{sed}_{\text {cum }}=\text { coef } *\left(Q * 10^{-3} * A * q_{p}\right)^{\text {exponent }} * K * C * P * L S * 10^{6}(4)
$$

where sed $_{\text {cum }}$ is the cumulative sediment yield at time step $j$ (in $\mathrm{g}$ ), $Q$ is the cumulative surface runoff volume (in $\mathrm{mm}$ ), $q_{p}$ is the peak runoff rate (in $\mathrm{m}^{3} / \mathrm{s}$ ), $A$ is the plot area (in $\mathrm{m}^{2}$ ), $K$ is the soil erodibility factor (Smith et al. ${ }^{34)}$ mentioned that $K$ is still in US units and is given in Agricultural Handbook 537 $7^{35)}$ as 0.01 ton. acre.h/(acre.ft-ton.in)), $C$ is the cover and management factor, $P$ is the support practice factor, and $L S$ is the topographic factor. $C$ is defined as the ratio of soil loss from land cropped under specified conditions to the corresponding loss from clean-tilled, continuous fallow. ${ }^{35)}$ In bare (or clean-tilled) soil, this ratio, $C$, is equal to 1.0. $P$ is given in the literature. ${ }^{35)}$ Without any support practice, $P$ equals 1.0.

The values coef and exponent of Eq. (4) were found by using the least squares error method. This method required the observed data of cumulative runoff, peak discharge, and sediment yields. If such data are not available, then the default values will be used. The default values for coef and exponent are 11.8 and 0.56 , respectively. ${ }^{34)}$ The soil erodibility factor $K$ is determined in the equation specified in the literature. ${ }^{36,37)}$ To help the user in the calibration/ validation of $K$, the coefficient of $K, K \_$coef (unitless), was initially added to the SPEC model to modify the initial $K$ as determined in the literature ${ }^{36,37)}$ to determine the final $K$.

\subsection{Pesticide simulation}

In this simulation, clothianidin and imidacloprid were selected. Both pesticides are neonicotinoid insecticides used widely in Japan for both paddy fields and upland fields to control pest insects. Although information about their use in upland fields is not available, clothianidin and imidacloprid production as active ingredients in Japan in 2017 totaled 337.2 tons and 82.0 tons (imidacloprid as an imported value), respectively. ${ }^{38)}$ Pesticide parameters such as the first order rate coefficients of photodegradation and biodegradation were determined in the previous study. ${ }^{8)}$ The pesticide masses in each layer were determined in a manner similar to that in Boulange et al. ${ }^{8)}$

In this study, two new terms were added to the pesticide calculation: the ratio of pesticide concentrations in mobile water and static water, $\alpha$; and the ratio of pesticide concentrations in runoff water and percolation water, $\beta$. The $\alpha$ and $\beta$ parameters account for the differences in pesticide concentrations in soil water, percolation water, and runoff water. These two parameters improve the results of pesticide concentration in soil water, runoff water, and percolation water. The terms $\alpha$ and $\beta$ are expressed in the equations as below:

$$
\alpha=\frac{C m w_{j, i}}{C s w_{j, i}}
$$


where $\alpha$ is the ratio of pesticide concentrations in mobile water and static water (unitless), and $\alpha=0$ when there is no runoff and no percolation; $C m w_{j, i}$ is the pesticide concentration in mobile water (in $\mathrm{mg} / \mathrm{L}$ ); and $C s w_{j, i}$ is the pesticide concentration in static water (in $\mathrm{mg} / \mathrm{L}$ ),

$$
\beta=\frac{C r w_{-} p s t_{j}}{C p e r_{j, 1}}
$$

where $\beta$ is the ratio of pesticide concentrations in runoff water and percolation water (unitless), and $\beta=0$ when there is no runoff; $C r w_{-} p s t_{j}$ is the pesticide concentration in runoff water in layer 1 (in $\mathrm{mg} / \mathrm{L}$ ); and $\mathrm{Cper}_{j, 1}$ is the pesticide concentration in percolation water from layer 1 (in $\mathrm{mg} / \mathrm{L}$ ).

The pesticide concentration in sediment is determined by

$$
\text { Csed }_{-} p s t_{j}=\varepsilon_{j} * C d s_{j, 1}
$$

where $C d s_{j, 1}$ is the pesticide concentration in dry soil layer 1 (in $\mathrm{mg} / \mathrm{kg}$ ), Csed_pst ${ }_{j}$ is the pesticide concentration in sediment (in $\mathrm{mg} / \mathrm{kg}$ ), and $\varepsilon_{j}$ is the pesticide enrichment ratio ${ }^{39)}$ and is determined by

$$
\varepsilon_{j}=e_{\text {coef }} *\left(\operatorname{Csed}_{j} / 1000\right)^{-0.2468}
$$

where $e_{\text {coef }}$ is the coefficient of the pesticide enrichment ratio. According to Menzel (1980), ${ }^{39)} e_{\text {coef }}$ equals 0.78. However, this parameter can be input in SPEC by the user.

The pesticide concentration in runoff water is determined by

$$
C r w_{-} p s t_{j}=\frac{d M r w_{-} p s t_{j}}{A * d Q_{j}}
$$

where $C r w_{-} p s t_{j}$ is the pesticide concentration in runoff water (in $\mathrm{mg} / \mathrm{L}$ ) and $d M r w_{-} p s t_{j}$ is the pesticide mass increment (in $\mathrm{mg}$ ) in runoff water; other terms are defined as above.

In this version of the SPEC model, multiple layers can be set by the user to calculate the pesticide concentrations in soil. In the SPEC model, the pesticide concentration in every soil layer is assumed to be a unique value for the whole layer depth. Therefore, it seems to be more accurate if the soil layer depth is small. Multiple layers allow the forecasting of pesticide concentrations in more than two layers. The two new parameters, $\alpha$ and $\beta$, improve the results of pesticide concentration in soil water, runoff water, and percolation water. The outputs are displayed dynamically in both table and charts. The VBA code was changed from a single variable to an array variable. The results of pesticide concentrations in soils are not presented in this paper.

\section{Sensitivity analysis, model calibration, and validation}

The Monte Carlo technique ${ }^{8,40)}$ was integrated into the SPEC model for sensitivity, calibration, validation, and uncertainty analyses. A sample size of $250^{8)}$ was selected for the Monte Carlo simulation. The strength of the parameters with a specific probability (95\% confidence level) was defined by the result of Monte Carlo simulation and regression analysis. Only parameters having a strong effect on the output were used for calibration and validation.
Model calibration is a procedure to determine parameters that fit the model output with corresponding observed data. ${ }^{41,42)}$ In this study, multi-stage calibrations ${ }^{43)}$ were conducted in turn for simulations of hydrology, sediment transport, and pesticide concentrations in runoff water and sediment. Model validation is a procedure to check the parameters obtained from calibration with another input dataset. ${ }^{41)}$ In this study, the experimental dataset for pesticide runoff from a $1 \mathrm{~m} \times 5 \mathrm{~m}$ bare soil plot under simulated rainfall obtained by Yadav and Watanabe ${ }^{44)}$ was used. For model calibration, the dataset of the first rainfall event for plot 1 was used, while the dataset of the first rainfall event for plot 2 was used for model validation.

\section{Model performance evaluation}

The model performance was evaluated using common statistical indexes, including the root mean square error (RMSE), coefficient of determination-R squared $\left(R^{2}\right)$, Nash-Sutcliffe Efficiency (NSE), and percent bias (PBIAS). These four statistical indexes were integrated into the SPEC model. The criteria for modelperformance evaluation (Supplemental Table S1) can be found in the study of Moriasi et al. (2007). ${ }^{45)}$

\section{Study area}

The Sakaecho field, located in Fuchu, Tokyo, Japan, was selected as a study area to test the model performance. ${ }^{44)}$ The experiments were conducted for three replicates of field plots under bare soil conditions with two artificial rainfall events. The plot has an area of $5 \mathrm{~m}^{2}$, a length of $5 \mathrm{~m}$, and a slope of $5 \%$.

Two types of pesticides, Dantotsu ${ }^{\circledR}$, containing 16\% clothianidin as an active ingredient, and Admiyer ${ }^{\circledR}$ Flowable, containing $20 \%$ imidacloprid as an active ingredient, were applied to the $1 \mathrm{~m} \times 5 \mathrm{~m}$ plot using a hand sprayer. The pesticide application date was September 26, 2017. The application rates of clothianidin and imidacloprid were 256 and $320 \mathrm{~g} / \mathrm{ha}$, respectively. Two artificial rainfall events (generated by a rainfall simulator) were conducted on October 2 and 10, 2017 (6 days and 14 days after the pesticide application day). Details of the mentioned data were shown in the study of Yadav and Watanabe. ${ }^{44}$

In every rainfall event, seven runoff samples in $60 \mathrm{~min}$ were collected, right after the first runoff, at a frequency of $10 \mathrm{~min}$, and in the amount of $1 \mathrm{~L}$ per sample. To minimize error, two consecutive values from every $10 \mathrm{~min}$ were used to calculate the average values and then to calculate the cumulative runoff and sediment. There were six datasets ( 2 rainfall events $\times 3$ plots) of pollutant runoff; however, only two datasets of pollutant runoff in plot 1 and plot 2 in the first rainfall event were satisfactory for calibration and validation. In the other four datasets, the slopes of the runoff graph were smaller than that generated by the NRSC method with zero initial abstraction; thus, these data were considered unrealistic. The details of the datasets are given in the Results and Discussion section.

The pesticide residues (clothianidin and imidacloprid) on October 2, 2017, were 249.0 and $294.9 \mathrm{~g} / \mathrm{ha}$, respectively. These values were calculated based on the initial pesticide mass in soil 
Table 1. Calibrated parameters for runoff and sediment transport

\begin{tabular}{lcccc}
\hline \multicolumn{1}{c}{ Parameter } & Symbol & Unit & Initial & Final \\
\hline Initial abstraction ratio & $\lambda$ & none & $0.01-0.2$ & 0.06 \\
Curve number & $\mathrm{CN}$ & none & $44-66$ & 59 \\
Coefficient of erodibility factor & $K \_c o e f$ & none & $0.8-1.5$ & 1.3 \\
Erodibility factor & $K$ & 0.01 ton.acre.h/(acre.ft-ton.in) & 0.2197 & 0.2856 \\
\hline
\end{tabular}

and the average degradation rate of pesticides, which was found by observing pesticide mass in the soil in the two plots used for the simulation. ${ }^{44)}$

Input data include the rainfall, evaporation, solar radiation, soil properties, coef, and exponent of MUSLE. The artificial rainfall was conducted on October 2, 2017. The intensity and duration of the rainfall were $70 \mathrm{~mm} / \mathrm{h}$ and $70 \mathrm{~min}$ for both plots, respectively. ${ }^{44)}$ The input time step of the rainfall was $1 \mathrm{~min}$. The temperature and related data for calculating evaporation and solar radiation were downloaded from the weather station near the study area. ${ }^{46)}$ Evaporation and solar radiation were calculated using the Food and Agriculture Organization (FAO) Penman-Monteith equation. ${ }^{47)}$ This work was done in a separate Excel file. The time step for temperature was hourly, and those for evaporation and solar radiation were daily.

Soil data, including soil type, bulk density, saturated water content, residual water content, and field capacity (Supplemental Table S2), were obtained from previous studies. ${ }^{848)}$ To test the model capacity for multiple-layer simulation, four soil layers $(0-1 \mathrm{~cm}, 1-5 \mathrm{~cm}, 5-10 \mathrm{~cm}$, and $10-15 \mathrm{~cm}$ in the study area) were entered into the SPEC model.

\section{Results and Discussion}

\section{The results of MUSLE parameters}

For sediment simulation, the coef and exponent of MUSLE for sed $_{\text {cum }}$ in Eq. (4) were entered into the SPEC model. They were determined based on observed data ${ }^{44)}$ using the least squares error method. Based on thirty-six sets of data ( 2 events $\times 3$ plots/ event $\times 6$ sets/plot) of cumulative runoff, sediment, and average peak discharge, the MUSLE values of coef and exponent were found to be 20924.9 and 1.053 , respectively. The agreement between simulated and observed sediment was very high, with an $R^{2}$ of 0.97 , NSE of 0.97 , PBIAS of $-0.04 \%$, and RMSE of $12.7 \%$.

\section{Sensitivity analysis, calibration, and validation}

Sensitivity analysis was conducted for the runoff rate output with parameters including the initial abstraction ratio $(\lambda), \mathrm{CN}$, residual and saturated water contents, and field capacity. It was found that only $\lambda$ and $\mathrm{CN}$ were sensitive to the runoff rate result. The standardized rank regression coefficients for $\lambda$ and $\mathrm{CN}$ were -8 and 0.08 , respectively. These two parameters were also sensitive to the cumulative runoff. The calibrated parameters of $\lambda$ and $\mathrm{CN}$ are shown in Table 1 . The calibrated $\lambda$ in the study was lower than the original value; it was similar to the values of $\lambda(0.05)$ in the previous studies ${ }^{23,26,27)}$ and was within the range of $\lambda(0-$ 0.142) for the rainfall event in the Hawkins study. ${ }^{22}$

For sediment transport outputs, the calibrated results of $K_{-}$coef and $K$ are shown in Table 1 . The validated $K$ of the study was 0.2856 , which is still in the validated range of $K(0.1$ to 0.5$\left.) .{ }^{36}\right)$

For pesticide concentrations in sediment and in runoff water, it was found that the calibrated coefficients of enrichment ratio $\left(\varepsilon_{j}\right)$ in Eq. (7) were 0.78 for both clothianidin and imidacloprid. The calibrated coefficient of the enrichment ratio agreed with that in Menzel's study. ${ }^{39)}$ The ratios of pesticide concentrations $(\alpha)$ in mobile and static water were 1.11 and 1.28 for clothianidin and imidacloprid, respectively, and the ratios of pesticide concentrations in runoff water and percolation water $(\beta)$ were 0.02 and 0.06 for clothianidin and imidacloprid, respectively. The higher values of $\alpha$ and $\beta$ for imidacloprid confirmed the higher observed imidacloprid concentrations in runoff water as compared to those for clothianidin. The result of this calibration may be related to the high water solubility of imidacloprid $(480 \mathrm{mg} / \mathrm{L})$ as compared to that of clothianidin $(327 \mathrm{mg} / \mathrm{L}) .{ }^{44)}$ With the additional parameters ( $\alpha$ and $\beta$ ), the SPEC model could generate the percent mass difference in runoff water for two types of pesticide, and thus those concentrations in runoff water fitted with the observed data and improved the model performance. The average percent mass loss (in calibration and validation) of imidacloprid in runoff water was

Table 2. Calibrated parameters of pesticides

\begin{tabular}{lcccc}
\hline \multicolumn{1}{c}{ Parameter } & Symbol & Unit & Clothianidin & Imidacloprid \\
\hline Coefficient of enrichment ratio & $e_{-}$coef & none & 0.78 & 0.78 \\
Ratio of pesticide concentrations in mobile and static waters & $\alpha$ & none & 1.11 & 1.28 \\
Ratio of pesticide concentrations in runoff and percolation waters & $\beta$ & none & 0.02 & 0.06 \\
Q10 & $Q 10$ & none & $1^{a)}$ & $149^{a)}$ \\
Biodegradation half-life & $\mathrm{HL}_{\mathrm{bio}}$ & $\mathrm{d}$ & $51^{a)}$ & $158^{b)}$ \\
Partitioning water/organic matter coefficient & $K_{\mathrm{oc}}$ & $\mathrm{L} / \mathrm{kg}$ & $86^{b)}$ &
\end{tabular}

a) These parameters were found by calculating bio-degradation which assuming no effect of temperature.

${ }^{b)}$ Ref. 44 
Table 3. Average values for pollutant runoff outputs in calibration and validation

\begin{tabular}{|c|c|c|c|c|c|}
\hline \multirow{2}{*}{ Average values } & \multirow{2}{*}{ Unit } & \multicolumn{2}{|c|}{ Calibration } & \multicolumn{2}{|c|}{ Validation } \\
\hline & & Obs. ${ }^{a)}$ & Sim. ${ }^{b)}$ & Obs. ${ }^{a)}$ & Sim. ${ }^{b)}$ \\
\hline Runoff rate & $\mathrm{cm} / \mathrm{h}$ & 2.09 & 2.29 & 2.51 & 2.29 \\
\hline Cumulative runoff & $\mathrm{cm}$ & 0.88 & 0.93 & 1.12 & 0.93 \\
\hline Sediment concentration & $\mathrm{g} / \mathrm{L}$ & 16.23 & 14.38 & 13.60 & 17.59 \\
\hline Sediment yield & g & 712.97 & 656.52 & 713.41 & 803.00 \\
\hline Clothianidin concentration in runoff water & $\mathrm{mg} / \mathrm{L}$ & 0.011 & 0.010 & 0.008 & 0.009 \\
\hline Clothianidin concentration in sediment & $\mathrm{mg} / \mathrm{kg}$ & 3.53 & 3.46 & 3.48 & 3.26 \\
\hline Imidacloprid concentration in runoff water & $\mathrm{mg} / \mathrm{L}$ & 0.028 & 0.027 & 0.019 & 0.027 \\
\hline Imidacloprid concentration in sediment & $\mathrm{mg} / \mathrm{kg}$ & 5.30 & 5.37 & 4.91 & 4.99 \\
\hline
\end{tabular}

a) Obs.: observed, ${ }^{b)}$ Sim.: simulated

$0.68 \%$ of applied imidacloprid mass. Similarly, the average percent mass loss (in calibration and validation) of clothianidin in runoff water was $0.35 \%$ of applied clothianidin mass. It was found that the average percent mass loss of imidacloprid in runoff water was higher than that of clothianidin. A higher Koc value (Table 2) of imidacloprid is probably related to the higher concentrations of imidacloprid than clothianidin in sediment (Table 3). The average percent mass loss (in calibration and validation) of imidacloprid in sediment was $2.32 \%$ of applied imidacloprid mass. Similarly, the average percent mass loss (in calibration and validation) of clothianidin in sediment was $2.00 \%$ of applied clothianidin mass. It was found that the average percent mass loss of imidacloprid in sediment was higher than that of clothianidin. Simulated concentrations of two types of pesticides in sediment and in runoff water (Table 3) were similar to those in the observation. ${ }^{44)}$

\section{Model outputs}

First, the results of hydrological simulation, including the time to first runoff, runoff rate, and cumulative runoff, are shown in Table 3, Fig. 1, and Fig. 2. The simulated times to first runoff, which were $10 \mathrm{~min}$, matched the observed data in both calibration and validation.

The average runoff rate and cumulative runoff were overestimated for calibration and underestimated for validation (Table 3). The difference may be due to the difference in water content and evaporation in two plots. However, the statistical indexes for the cumulative runoff $\left(R^{2}>0.8\right.$, NSE $>0.75$, PBIAS $\left.< \pm 20 \%\right)$ indicated a very good model performance, and those for the runoff rate $\left(R^{2}>0.8\right.$, NSE $>0.5$, PBIAS $\left.< \pm 10 \%\right)$ indicated a reasonable model performance (Table 4 ). It can be seen from Fig. 1 and Fig. 2 that the model performances were very good for the cumulative runoff and good for the runoff rate.

Next, the results of sediment transport, including sediment yields and concentrations, are shown in Table 3, Fig. 3, and Fig. 4. The results of sediment yields and concentrations were underestimated in calibration and overestimated in validation (Table
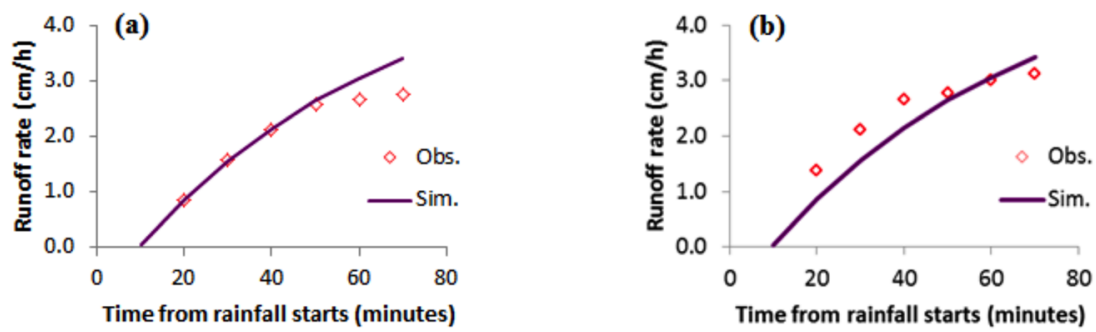

Fig. 1. Runoff rates in (a) calibration and (b) validation
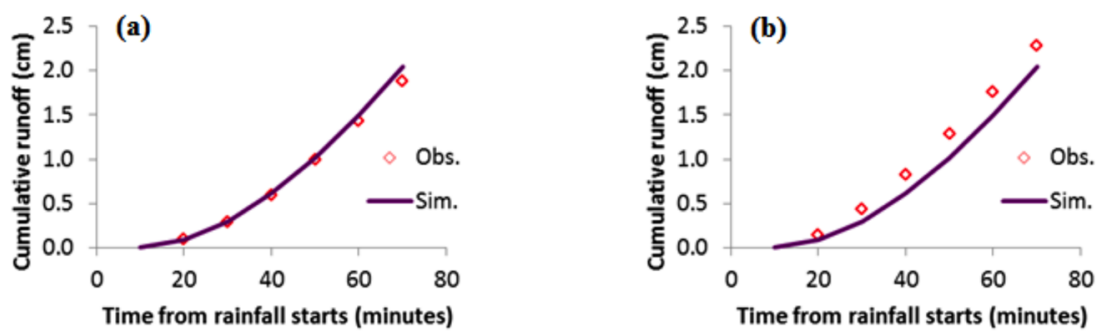

Fig. 2. Cumulative runoffs in (a) calibration and (b) validation 
Table 4. Model performance of pollutant runoff outputs

\begin{tabular}{|c|c|c|c|c|c|c|c|c|}
\hline \multirow{2}{*}{ Statistical results } & \multicolumn{4}{|c|}{ Calibration } & \multicolumn{4}{|c|}{ Validation } \\
\hline & RMSE (\%) & $R^{2}(-)$ & $\operatorname{NSE}(-)$ & PBIAS (\%) & RMSE (\%) & $R^{2}(-)$ & $\operatorname{NSE}(-)$ & PBIAS (\%) \\
\hline Runoff rate & 15.1 & 0.96 & 0.79 & -9.5 & 15.8 & 0.94 & 0.56 & 9.0 \\
\hline Cumulative runoff & 8.3 & 1 & 0.99 & -5.1 & 18.9 & 1 & 0.92 & 17.5 \\
\hline Sediment concentration & 14.9 & 0.8 & -0.16 & 11.4 & 39.5 & 0.76 & -0.47 & -29.3 \\
\hline Sediment yield & 9.9 & 1 & 0.98 & 7.9 & 14.7 & 1 & 0.97 & -12.6 \\
\hline Clothianidin concentration in runoff water & 42.1 & 0.92 & 0.51 & 9.5 & 41.0 & 0.72 & 0.49 & -16.9 \\
\hline Clothianidin concentration in sediment & 22.0 & 0.98 & 0.23 & 2.0 & 13.0 & 0.95 & 0.89 & 6.2 \\
\hline Imidacloprid concentration in runoff water & 52.2 & 0.79 & 0.28 & 1.5 & 58.0 & 0.57 & -0.16 & -38.4 \\
\hline Imidacloprid concentration in sediment & 13.3 & 0.88 & 0.76 & -1.4 & 11.5 & 0.93 & 0.92 & -1.6 \\
\hline
\end{tabular}

3). The underestimated sediment yield in calibration was due to the smaller runoff coefficient (the observed total runoff was lower than that in validation under the same rainfall amount), while the simulated cumulative runoff had the same value for both calibration and validation and vice versa for validation. In calibration, due to the underestimated sediment increment and the overestimated runoff increment, the sediment concentration was underestimated, and vice versa for validation. However, the sediment yield graphs (Fig. 3) performed very well with the observed data. The statistical indexes for the sediment yields $\left(R^{2}>0.8\right.$, NSE $>0.75$, PBIAS $< \pm 15 \%$ ) also indicated a very good model performance (Table 4). For sediment concentrations, although the NSE values were negative, the $R^{2}$ values for sediment concentrations were high $\left(R^{2} \geq 0.76\right)$, and the PBIAS values for sediment concentrations were low (PBIAS $< \pm 30 \%$ ) (Table 4 ). A high $R^{2}$ for sediment concentrations indicated that there were good agreements between the trends of simulated and observed data (Table 4).

Finally, the results of the average concentrations of clothianidin and imidacloprid in sediment and runoff water are shown in Table 3. The average concentrations of clothianidin in sediment were underestimated in both calibration and validation (Table 3 ). The average concentrations of clothianidin in runoff water were underestimated in calibration but overestimated in validation (Table 3). However, for both calibration and validation, the statistical indexes for clothianidin concentrations in sediment $\left(R^{2}>0.8\right.$, NSE $>0.2$, PBIAS $\left.< \pm 25 \%\right)$ and in runoff water $\left(R^{2}>0.7\right.$, NSE $\approx 0.5$, PBIAS $\left.< \pm 25 \%\right)$ indicated an acceptable model performance (Table 4). Figure 5 shows a good prediction for clothianidin concentrations in sediment, while a reasonable prediction of clothianidin concentration in runoff water can be seen in Fig. 6. The concentrations of clothianidin in sediment (Fig. 5) and in runoff water (Fig. 6) decreased from the beginning to the end of runoff for both calibration and validation. These trends agreed with those in previous studies. ${ }^{49,50)}$

The average concentrations of imidacloprid in sediment were overestimated in both calibration and validation (Table 3 ). Similar to the average concentrations of clothianidin in runoff water, those of imidacloprid were underestimated in calibration but overestimated in validation (Table 3). Nevertheless, the statistical indexes in both calibration and validation for
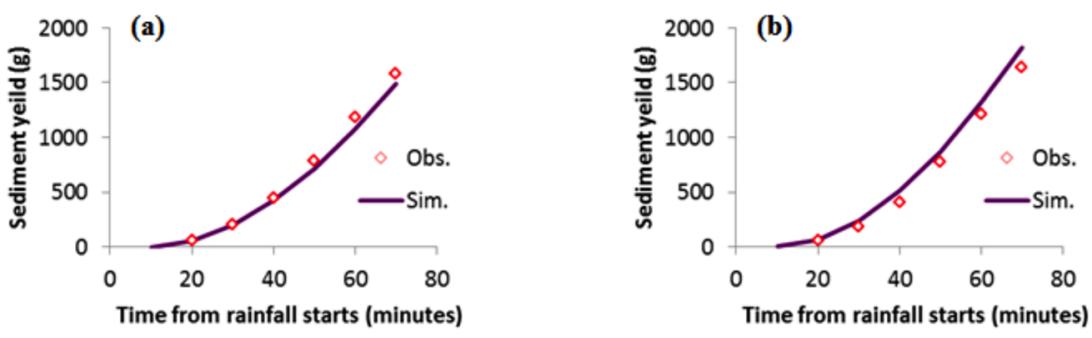

Fig. 3. Cumulative sediment yields in (a) calibration and (b) validation
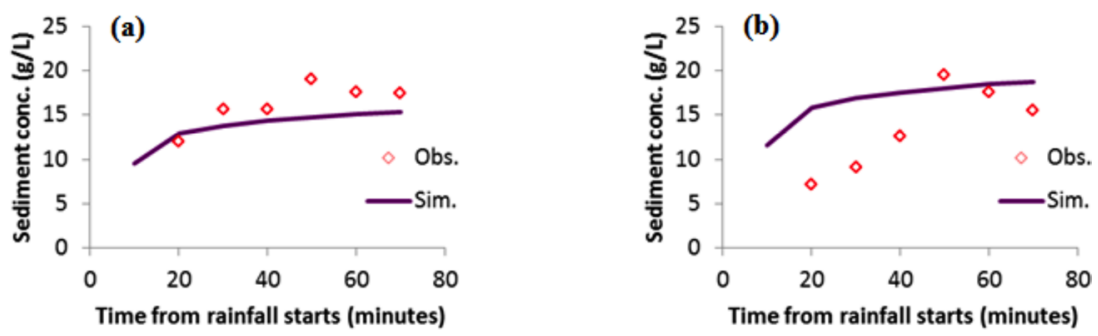

Fig. 4. Sediment concentrations in (a) calibration and (b) validation 

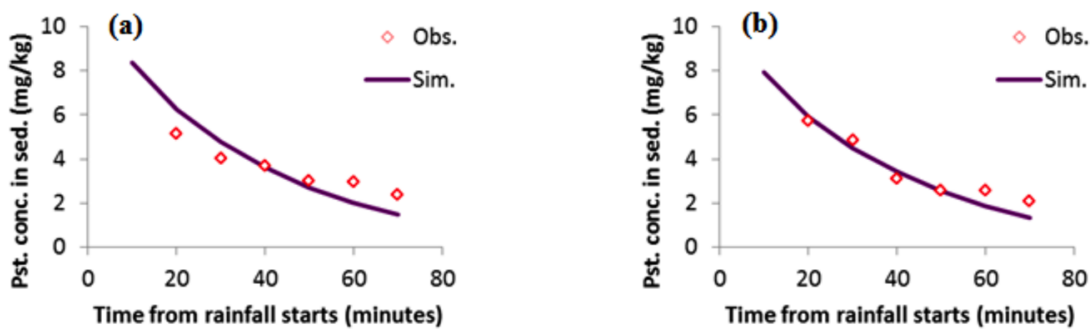

Fig. 5. Clothianidin concentrations in sediment in (a) calibration and (b) validation
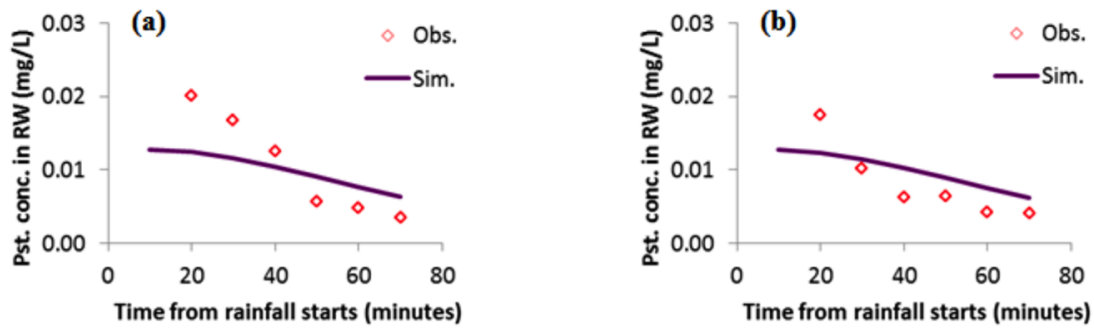

Fig. 6. Clothianidin concentrations in runoff water in (a) calibration and (b) validation

imidacloprid concentrations in sediment $\left(R^{2}>0.8\right.$, NSE $>0.75$, PBIAS $< \pm 25 \%)$ indicated a very good model performance (Table 4). Although the NSE value was negative in validation for the imidacloprid concentration in runoff water, the $R^{2}$ $\left(R^{2} \geq 0.57\right)$ and PBIAS (PBIAS $\left.< \pm 40 \%\right)$ indicated an acceptable performance for both calibration and validation (Table 4). A visual display indicates a good and reasonable performance for imidacloprid concentrations in sediment (Fig. 7) and in runoff water (Fig. 8), respectively. A trend similar to that for clothianidin was found for imidacloprid. The concentrations of imidacloprid in sediment (Fig. 7) and in runoff water (Fig. 8) decreased from the beginning to the end of runoff for both calibration and validation. These trends also matched the observed trends and agreed with those in previous studies. ${ }^{49,50)}$

\section{Conclusion}

The pollutant runoff model was successfully coded and integrated into the SPEC model. The additional codes for Monte Carlo simulation as well as statistical indexes were integrated into the SPEC model to support the procedures of sensitivity analysis, calibration, and validation, as well as to evaluate the model performance.

The simulation results of the Sakaecho farm case study implied the model's capacity to predict the runoff water (both runoff rate and cumulative runoff), sediment yield, and pesticide
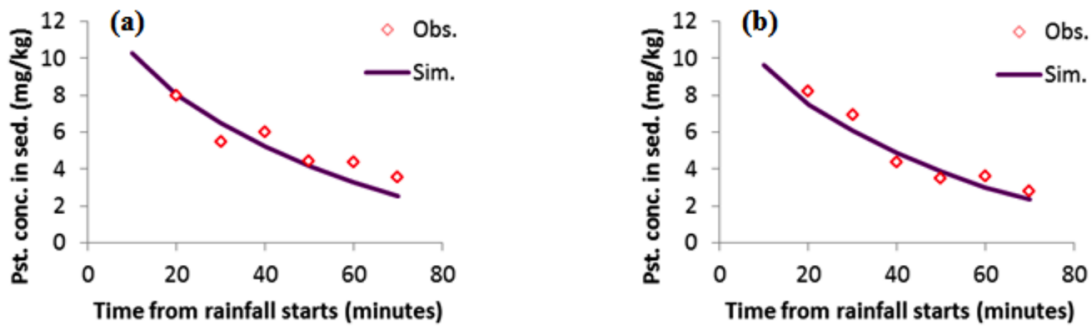

Fig. 7. Imidacloprid concentrations in sediment in (a) calibration and (b) validation
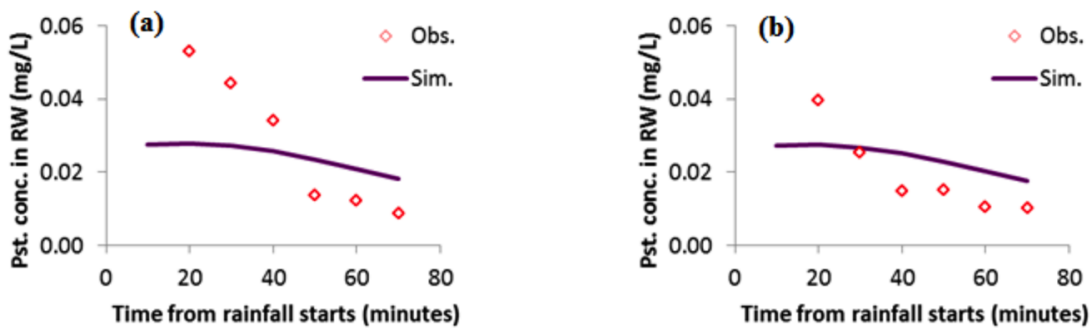

Fig. 8. Imidacloprid concentrations in runoff water in (a) calibration and (b) validation 
concentrations in runoff sediment and in runoff water under artificial rainfall conditions. Future research should be conducted with other rainfall intensities and pesticide to test the pollutant runoff model performance.

\section{Acknowledgements}

This study was funded in part by the Can Tho University Improvement Project VN14-P6, supported by a Japanese ODA loan. The authors appreciate all members from Pesticide Fate and Transport Laboratory, Tokyo University of Agriculture and Technology, Japan for their helps of data collection.

\section{References}

1) National Research Council: "Pesticides in the Diets of Infants and Children", National Academies Press, Washington, DC (1993).

2) World Health Organization: 2008. http://www.who.int/ceh/capacity/ Pesticides.pdf (Accessed 10 Sep., 2018).

3) K. Inao and Y. Kitamura: Pestic. Sci. 55, 38-46 (1999).

4) J. R. Williams, N. Kannan, X. Wang, C. Santhi and J. G. Arnold: J. Hydrol. Eng. 17, 1221-1229 (2012).

5) R. Zhang, A. J. Krzyszowska-Waitkus, G. F. Vance and J. Qi: Adv. Environ. Res. 4, 57-65 (2000).

6) O. Varis: Water Qual. Int. 96, 109-117 (1996).

7) J. Boulange, H. Watanabe, K. Inao, T. Iwafune, M. Zhang, Y. Luo and J. Arnold: J. Hydrol. (Amst.) 517, 146-156 (2014).

8) J. Boulange, D. Q. Thuyet, P. Jaikaew, S. Ishihara and H. Watanabe: $J$. Pestic. Sci. 41, 152-162 (2016).

9) L. Hoang Tu, J. Boulange, T. Iwafune, I. Yadav and H. Watanabe: Pest Manag. Sci. 74, 2520-2529 (2018).

10) A. Numabe and S. Nagahora: Water Sci. Technol. 53, 139-146 (2006).

11) K. Inao, H. Watanabe, D. G. Karpouzas and E. Capri: Jpn. Agric. Res. Q. 42, 13-21 (2008)

12) H. Watanabe and K. Takagi: Environ. Technol. 21, 1379-1391 (2000).

13) A. C. L. Franco and N. B. Bonumá: RBRH 22 (2017).

14) N. Kannan, S. M. White, F. Worrall and M. J. Whelan: J. Hydrol. (Amst.) 332, 456-466 (2007).

15) K. W. King, J. G. Arnold and R. L. Bingner: Trans. ASAE 42, 919-926 (1999).

16) T. Kowalik and A. Walega: Water 7, 939-955 (2015).

17) M. Nearing, B. Liu, M. Risse and X. C. Zhang: Am. Water Resour. Assoc. 32, 125-136 (1996).

18) P. T. S. Oliveira, M. A. Nearing, R. H. Hawkins, J. J. Stone, D. B. B. Rodrigues, E. Panachuki and E. Wendland: J. Soil Water Conserv. 71, 420-429 (2016).

19) W. J. Rawls and D. L. Brakensiek: Trans. ASAE 29, 1597-1599 (1986).

20) K. X. Soulis and J. D. Valiantzas: Hydrol. Earth Syst. Sci. 16, 10011015 (2012)

21) I. Ahmad, V. Verma and M. K. Verma: Application of Curve Number Method for Estimation of Runoff Potential in GIS Environment, presented at the 2nd International Conference on Geological and Civil Engineering, 2015, Singapore, IACSIT Press.

22) R. H. Hawkins, T. J. Ward, E. Woodward and J. A. V. Mullem: Continuing evolution of rainfall-runoff and the Curve Number precedent, presented at the 2nd Joint Federal Interagency Conference, 2010, Las Vegas, NV, 1-12.

23) K. J. Lim, B. A. Engel, S. Muthukrishnan and J. Harbor: J. Am. Water Resour. Assoc. 42, 629-643 (2006).

24) J. Rajbanshi: J. Civ. Environ. Eng. 6, 1-6 (2016).
25) S. Satheeshkumar, S. Venkateswaran and R. Kannan: Model. Earth Syst. Environ. 3, 24 (2017).

26) Z.-H. Shi, L.-D. Chen, N.-F. Fang, D.-F. Qin and C.-F. Cai: Catena 77, $1-7$ (2009).

27) D. E. Woodward, R. H. Hawkins and R. Jiang: J. Allen T. Hjelmfelt, J. A. V. Mullem, and Q. D. Quan: "Runoff Curve Number Method: Examination of the Initial Abstraction Ratio", World Water Environ. Resour. Congr. 2003 (2003).

28) Y. Yuan, W. Nie, S. C. McCutcheon and E. V. Taguas: Hydrol. Processes 28, 774-783 (2012).

29) USDA Natural Resources Conservation Service: "Chapter 5: Streamflow Data," 2015.

30) USDA Natural Resources Conservation Service: "Chapter 10: Estimation of Direct Runoff from Storm Rainfall,” 2004.

31) USDA Natural Resources Conservation Service: "Module 205. SCS Runoff Equation," National Employee Development Center, 1999.

32) S. L. Neitsch, J. G. Arnold, J. R. Kiniry and J. R. Williams: "Soil and Water Assessment Tool Theoretical Documentation Version 2009", Texas Water Resources Institute (2011).

33) J. R.Williams: "Sediment-yield prediction with Universal Equation using runoff energy factor", USDS. ARS-S40, pp. 244-252, (1975).

34) S. J. Smith, J. R. Williams, R. G. Menzel and G. A. Coleman: J. Range Manage. 37, 295-297 (1984).

35) W. H. Wischmeier and D. D. Smith: "Predicting rainfall erosion losses: A guide to conservation planning", U.S. Dep. Agric., Agric. Handb. No. 537 (1978).

36) A. N. Sharpley and J. R. Williams: "EPIC-Erosion/Productivity Impact Calculator: 1. Model Documentation", U.S. Department of Agriculture Technical Bulletin No. 1768 (1990).

37) J. R. Williams: "The EPIC Model," Water Resources Publications, pp. 909-1000, 1995

38) Japan Plant Protection Association: "Nouyaku Youran," Tokyo (2018) (in Japanese).

39) R. G. Menzel: "Chapter 12. Enrichment ratios for water quality modelling”, USDA-SEA-Conserv. Res. Report No. 26, pp. 486-492, 1980.

40) K. Kondo, J. Boulange, T. K. Phong, K. Hiramatsu, T. Inoue and H. Watanabe: J. Pestic. Sci. 37, 312-322 (2012).

41) C. Santhi, J. G. Arnold, J. R. Williams, W. A. Dugas, R. Srinivasan and L. M. Hauck: J. Am. Water Resour. Assoc. 37, 1169-1188 (2001).

42) P. O. Yapo, H. V. Gupta and S. Sorooshian: J. Hydrol. (Amst.) 204, 83-97 (1998).

43) A. C. Armstrong, A. M. Portwood, P. B. Leeds-Harrison, G. L. Harris and J. A. Catt: Pestic. Sci. 48, 47-55 (1996).

44) I. C. Yadav and H. Watanabe: Sci. Total Environ. 640-641, 1354-1364 (2018).

45) D. N. Moriasi, J. G. Arnold, M. W. Van Liew, R. L. Bingner, R. D. Harmel and T. L. Veith: Trans. ASABE 50, 885-900 (2007).

46) Japan Meteorological Agency: http://www.data.jma.go.jp/obd/stats/ etrn/view/hourly_al.php?prec_no $=44 \&$ block_no $=1133 \&$ \&ear $=201$ $7 \&$ month $=09 \&$ day $=01 \&$ view $=$ p1 (Accessed 10 Oct., 2017).

47) FAO: Crop Evapotranspiration-Guidel. Comput. Crop Water Requir. FAO Irrig. Drain. Pap. 56, 1998. http://www.fao.org/docrep/X0490E/ x0490e06.htm (Accessed 5 Sep., 2017).

48) P. Jaikaew, J. Boulange, D. Q. Thuyet, F. Malhat, S. Ishihara and H. Watanabe: Springer Int. Publ. Switz. (2015)

49) H. Watanabe and M. E. Grismer: J. Hydrol. (Amst.) 247, 183-199 (2001).

50) H. Watanabe and M. E. Grismer: J. Environ. Manage. 69, 157-168 (2003). 